\title{
Manejo agroecológico do solo em áreas sob o cultivo de hortículas no Município de Corrente, Piauí
}

\author{
Tancio Gutier Ailan Costa ${ }^{1}$, Juliana Vogado Coelho' ${ }^{1}$, Monyzia de \\ Souza Batista ${ }^{1}$, Maury Moreira Timóteo ${ }^{1}$, Alessandra de Souza Lago², \\ Rejane Barbosa Santos², Patrícia Lima da Silva², Bruna de Freitas \\ Iwata $^{3}$
}

${ }^{1}$ Instituto Federal de Educação, Ciência e Tecnologia do Piauí. Av. Presidente Jânio Quadros, 330. Santa Isabel. Teresina-PI (CEP 64053-390). Graduando em Tecnologia em Gestão Ambiental.

${ }^{2}$ Instituto Federal de Educação, Ciência e Tecnologia do Piaú. Av. Presidente Jânio Quadros, 330. Santa Isabel. Teresina-PI (CEP 64053-390). Graduado em Tecnologia em Gestão Ambiental.

${ }^{3}$ Instituto Federal de Educação, Ciência e Tecnologia do Piauí. Av. Presidente Jânio Quadros, 330. Santa Isabel. Teresina-PI (CEP 64053-390). Curso em Tecnologia em Gestão Ambiental. E-mail: iwata@ifpi.edu.br.

Resumo. O uso e o manejo agrícola do solo têm sido objetos de preocupação em escala mundial, haja vista que os níveis de degradação influenciam tanto na produção de alimentos quanto nas características ambientais desse recurso. Assim o emprego de técnicas não apropriadas de manejo do solo no uso agrícola leva a uma consequente perda de qualidade e consequentemente perda de produtividade. Desta forma, em consideração a busca pela estabilidade e sustentabilidade nos sistemas de produção agrícola, o presente estudo teve como objetivo caracterizar o manejo sustentável e a qualidade do solo sob a agricultura familiar no Município de Corrente-PI. A pesquisa foi realizada através de levantamento de campo, baseado em observações in loco e aplicação de questionários semiestruturado aos agricultores para caracterização e identificação do manejo adotado bem como coletas de solo na profundidade 0 a $20 \mathrm{~cm}$ composta de três repetições para avaliação da qualidade do solo de acordo com as análises de seus atributos. As amostras foram encaminhadas para o Instituto Federal do Piauí, Campus Corrente, onde foram determinados a umidade e a densidade do solo, por diferença de massa, e o teor de matéria orgânica, empregando o fator de correção de acordo com metodologia indicada. Verificou-se que as áreas estudadas caracterizam-se como sendo áreas agrícolas de caráter agroecológico, uma vez que fazem uso de técnicas conservacionistas do solo, e que estas se mostram eficientes na manutenção da qualidade do solo, promovendo influência sobre seus atributos físicos e os teores de matéria orgânica do solo comparados aos atributos referência da mata nativa testemunha.

Palavras-chave: Manejo conservacionista do solo, Material orgânico, Qualidade do solo.

Recebido: 20/11/2015

Aceito: 14/12/2015

Publicado: 31/12/2015

Acesso Aberto Artigo completo

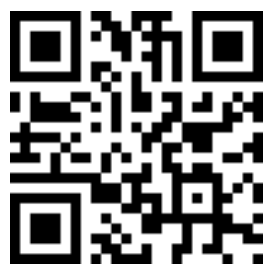




\begin{abstract}
Agroecological soil management in areas under horticultural cultivation in the Corrente Municipality, Piauí State.
\end{abstract} The use and agricultural soil management have been the object of concern on a global scale, given that the levels of degradation influence both in food production and in the environmental characteristics of this resource. Thus the use of expropriated land management techniques in agricultural use leads to a consequent loss of quality and consequently lost productivity. Thus, consider the quest for stability and sustainability in agricultural production systems, this study aimed to characterize the sustainable management and soil quality on family farms in the Corrente Municipality, Piauí State. The survey was conducted through field survey, based on observations in the field and application of semi-structured questionnaires to farmers for characterization and identification of management adopted and soil sampling at the depth $0-20 \mathrm{~cm}$ composed of three replications for assessment of soil quality according to the opinion of its attributes. The samples were sent to Federal Institute of the Piauí, Campus Corrente, where it was determined moisture and bulk density by mass difference and organic matter content using the correction factor according to specified methodology. It was found that the areas studied are characterized as agricultural areas of agro-ecological character, as make use of conservation land techniques, and these are shown effective in maintaining soil quality by promoting influences on their physical attributes and levels of soil organic matter compared to reference attributes of native witness kills.

Keywords: Conservation management of soil, Organic matter, Soil quality.

\section{Introdução}

O uso e manejo agrícola do solo têm sido objetos de preocupação em escala mundial, haja vista que os níveis de degradação influenciam tanto na produção de alimentos quanto nas características ambientais desse recurso. Assim o emprego de desapropriadas técnicas de manejo do solo no uso agrícola leva a uma perda de qualidade e consequentemente perda de produtividade.

Segundo Costa (2014), a degradação ambiental de áreas agrícolas que afeta o processo produtivo do solo é condição relevante para o desenvolvimento de agricultura sustentável, garantindo o seu uso e manejo mais eficiente. O processo de produção agrícola possibilita alterações adversas causando um desequilíbrio às condições naturais dos recursos. Entretanto no desenvolvimento da agricultura as ações contribuem para os possíveis impactos em áreas produtivas uma vez que o uso sem aplicações de técnicas sustentáveis provocam consequências que afetam a qualidade ambiental.

Ao considerar que o recurso solo é limitado e que alguns de seus componentes requerem períodos de tempo prolongados para serem restaurados, a previsão do grau das perturbações ambientais provocadas pelo manejo inadequado das atividades agropecuárias se torna essencial (Stefanoski et al., 2013).

De acordo a importância do manejo adequado tanto do solo como da água Carvalho et al. (2007), afirmam que este é um pré-requisito que se deve ter sempre em mente quando se propõe estabelecer sistemas sustentáveis de cultivo. Nesse sentido, o manejo do solo nestas áreas é de fundamental importância, pois influencia diretamente em sua qualidade, além de ser relevante no processo de conservação, tendo em vista uma série de impactos que podem ser gerados no e sobre o solo. 
Diante dos processos de degradação ambiental tem-se buscado modelos de produção agrícola sustentável que vise respeitar os preceitos ecológicos, da conservação do meio ambiente e do bemestar do ser humano. A produção orgânica se enquadra neste contexto e no Brasil, em que cada vez mais, vem conquistando tanto no âmbito da agricultura familiar como no seguimento empresarial formado por médios e grandes produtores rurais (Gliessman, 2000).

Partindo da necessidade de manutenção e da qualidade dos solos, conhecer o manuseio dos solos adotados pelos agricultores é relevante para avaliar o desenvolvimento e a sustentabilidade de práticas agrícolas locais, além de proporcionar uma melhor compreensão dos procedimentos e métodos adotados pelos agricultores.

Desta forma, em consideração a busca pela estabilidade e sustentabilidade nos sistemas de produção agrícola, o presente estudo teve como objetivo caracterizar o manejo sustentável e a qualidade do solo sob a agricultura familiar no Município de Corrente-PI.

\section{Material e métodos}

\section{Áreas de estudo}

$\mathrm{O}$ estudo foi realizado no Município de Corrente, situado no extremo sul do Estado do Piaú́, localizado na coordenada geográfica de referência $10^{\circ} 26^{\prime} 34^{\prime \prime}$ S e $45^{\circ} 09^{\prime} 43^{\prime \prime}$ W, com altitude de $438 \mathrm{~m}$. Sua população estimada é de 25.408 habitantes (Figura 1). O município está inserido na Microrregião das Chapadas do Extremo Sul Piauiense, compreendendo área de 3.033,66 km². O clima enquadra-se no tipo tropical úmido, com temperatura média de $25^{\circ} \mathrm{C}$ (IBGE, 2010).

Para execução da presente pesquisa foram escolhidas duas comunidades rurais do Munícipio de Corrente e outra área localizada no perímetro urbano, sendo elas Calumbi, Simplício e Horta Comunitária.

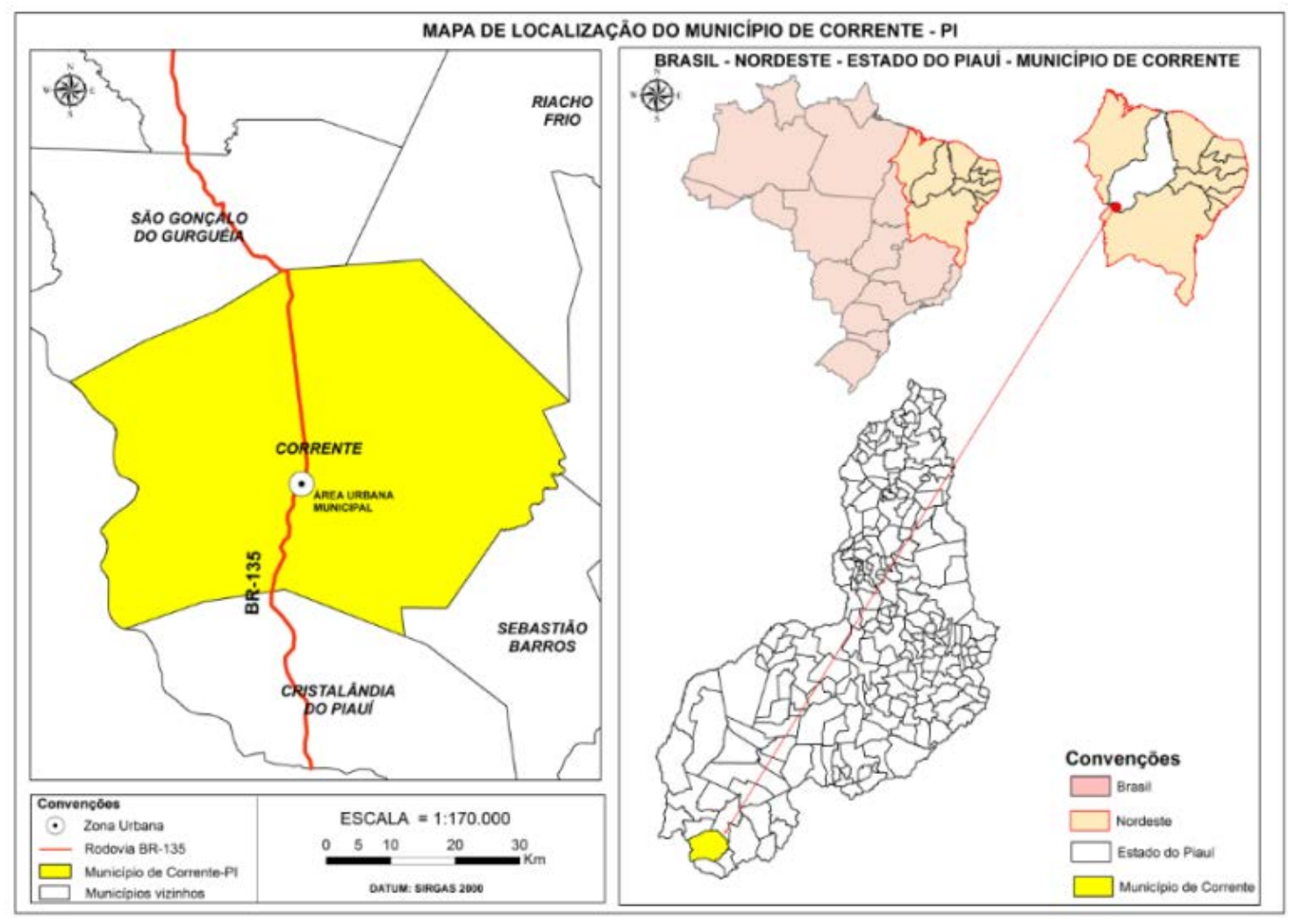

Figura 1. Localização do Município de Corrente, Piauí. Fonte: Antônio Celso de Sousa Leite. 


\section{Aspectos metodológicos}

A pesquisa foi realizada através de visitas in loco na qual aplicou-se questionários semiestruturado aos agricultores das áreas selecionadas para identificação e descrição do manejo adotado. Para avaliar a qualidade do solo das comunidades de estudo, foram selecionadas as hortas correspondentes a sua totalidade como também em área sob Mata Nativa do Cerrado (MNC), nas quais se coletou amostras de solo na profundidade de 0 a 20 cm, compostas de três repetições.

As amostras foram coletadas considerando a sazonalidade da região, composta por um período seco que vai de maio a novembro e outro período chuvoso que vai de dezembro a abril. As amostras foram levadas para o Laboratório de Biologia do Instituto Federal do Piauí, Campus Corrente, na qual se determinou umidade e densidade do solo, por diferença de massa. A umidade do solo (\%) foi determinada pela diferença de massa e a densidade do solo pelo método do anel volumétrico (g.cm ${ }^{-3}$ ).
A matéria orgânica (MO) foi calculada pela determinação dos teores de carbono orgânico total do solo (COT), pela metodologia de Yeomans e Bremner (1988), e estimado o teor de matéria orgânica empregando o fator de correção $M O=1,724 \times C O T$. Os dados foram submetidos à análise de variância pelo Teste T, utilizando o software Assistat 7.7.

\section{Resultados e discussão}

O estudo constatou que as práticas de manejo do solo adotadas nas hortas agroecológicas das comunidades rurais do Município de Corrente caracterizam-se principalmente pelo cultivo de tuberosas e herbáceas, o quetipifica as práticas hortícolas convencionais, por não promoverem um cultivo variado em suas áreas. Pôde-se observar que as técnicas de manejo utilizadas nas hortas não apresentaram variações significativas quanto as suas estratégias de preparo do solo, forma de nutrição e suas técnicas agroecológicas adotadas (Tabela 1).

Tabela 1. Descrição do manejo do solo adotado em hortas pelos agricultores nas zonas rurais do Município de Corrente, Piauí.

\begin{tabular}{|c|c|c|c|c|c|}
\hline Áreas & Cultivos & Preparo do solo & Nutrição do solo & $\begin{array}{c}\text { Controle de } \\
\text { pragas }\end{array}$ & TAM* \\
\hline $\mathrm{AlC}$ & $\begin{array}{l}\text { Cebolinha, coentro, } \\
\text { alface, rúcula, couve, } \\
\text { tomate, pimentão, salsa, } \\
\text { cenoura, beterraba, } \\
\text { espinafre, etc. }\end{array}$ & $\begin{array}{l}\text { Realizado por } \\
\text { enxada manual, na } \\
\text { qual se mede a area } \\
\text { em que se puxa a } \\
\text { linha de plantio, } \\
\text { abre-se a cava e } \\
\text { semeia. }\end{array}$ & $\begin{array}{l}\text { Uso de adubo } \\
\text { mineral: NPK } \\
\text { formulado. Uso } \\
\text { de adubo } \\
\text { orgânico: esterco } \\
\text { bovino erestos de } \\
\text { culturas. }\end{array}$ & $\begin{array}{l}\text { Uso } \\
\text { defensivos } \\
\text { agricolas. }\end{array}$ & $\begin{array}{l}\text { Cultivo em faixa, rotação } \\
\text { de culturas, e plantio } \\
\text { direto. }\end{array}$ \\
\hline $\mathrm{A} 2 \mathrm{C}$ & $\begin{array}{l}\text { Cebolinha, coentro, } \\
\text { alface, rúcula, couve, } \\
\text { tomate, pimentäo, salsa, } \\
\text { cenoura, beterraba, } \\
\text { rabanete, mamão, } \\
\text { maracujá, feijäo, milho } \\
\text { etc. }\end{array}$ & $\begin{array}{l}\text { Realizado por } \\
\text { enxada manual, na } \\
\text { qual cava-se em } \\
\text { linha, faz a ruma do } \\
\text { canteiro e semeia. }\end{array}$ & $\begin{array}{l}\text { Uso de adubo } \\
\text { orgânico: esterco } \\
\text { bovino e restos de } \\
\text { culturas. }\end{array}$ & Retirada manual. & $\begin{array}{l}\text { Rotação de culturas e } \\
\text { plantio direto. }\end{array}$ \\
\hline $\mathrm{A} 3 \mathrm{C}$ & $\begin{array}{l}\text { Coentro, abobora, cebola, } \\
\text { cebolinha, alface, rúcula, } \\
\text { couve, tomate, pimentão, } \\
\text { salsa, cenoura, beterraba, } \\
\text { rabanete, cenoura, } \\
\text { espinafre, melancia, } \\
\text { maracujá, feijão, milho } \\
\text { etc. }\end{array}$ & $\begin{array}{l}\text { Realizado por } \\
\text { enxada manual, na } \\
\text { qual se cava-se a } \\
\text { ruma do canteiro e } \\
\text { semeia. }\end{array}$ & $\begin{array}{l}\text { Uso de adubo } \\
\text { orgânico: esterco } \\
\text { bovino; } \\
\text { compostos } \\
\text { orgânicos e restos } \\
\text { de culturas. }\end{array}$ & Retirada manual. & $\begin{array}{l}\text { Rotação de culturas, } \\
\text { plantio direto e adubação } \\
\text { verde. }\end{array}$ \\
\hline
\end{tabular}


Tabela 1. Continuação.

\begin{tabular}{|c|c|c|c|c|c|}
\hline Als & $\begin{array}{l}\text { Alface, cebolinha, } \\
\text { coentro, rúcula, couve, } \\
\text { tomate, pimentăo, salsa, } \\
\text { cenoura, beterraba, } \\
\text { rabanete, etc. }\end{array}$ & $\begin{array}{l}\text { Realizado por } \\
\text { enxada manual, onde } \\
\text { limpa-se o terreno } \\
\text { prepara-se o canteiro } \\
\text { e semeia-se } \\
\text { manualmente. }\end{array}$ & $\begin{array}{l}\text { Uso de adubo } \\
\text { orgânico: esterco } \\
\text { bovino. }\end{array}$ & Retirada manual. & $\begin{array}{l}\text { Plantio direto, rotação de } \\
\text { culturas, cultivo em faixa } \\
\text { e. }\end{array}$ \\
\hline $\mathrm{A} 2 \mathrm{~S}$ & $\begin{array}{l}\text { Salsa, coentro, cebolinha, } \\
\text { alface, rúcula, couve, } \\
\text { tomate, pimentão, } \\
\text { cenoura, beterraba, } \\
\text { rabanete, espinafre etc. }\end{array}$ & $\begin{array}{l}\text { Realizado por } \\
\text { enxada manual, onde } \\
\text { cava-se em linha, } \\
\text { prepara a pilha e } \\
\text { planta-se. }\end{array}$ & $\begin{array}{l}\text { Uso de adubo } \\
\text { orgânico: esterco } \\
\text { bovino e restos de } \\
\text { culturas. }\end{array}$ & Retirada manual. & $\begin{array}{l}\text { Cultivo em faixa, plantio } \\
\text { direto, e rotação de } \\
\text { culturas. }\end{array}$ \\
\hline A 3 S & $\begin{array}{l}\text { Couve, cebolinha, } \\
\text { coentro, alface, rúcula, } \\
\text { tomate, pimentăo, salsa, } \\
\text { cenoura, } \quad \text { beterraba, } \\
\text { rabanete, } \quad \text { maracuja, } \\
\text { feijão, etc. }\end{array}$ & $\begin{array}{l}\text { Realizado por } \\
\text { enxada manual, na } \\
\text { qual cava-se em } \\
\text { linha, faz a ruma do } \\
\text { canteiro e semeia. }\end{array}$ & $\begin{array}{l}\text { Uso de adubo } \\
\text { orgânico: restos } \\
\text { de culturas e } \\
\text { esterco bovino. }\end{array}$ & $\begin{array}{l}\text { Retirada manual e } \\
\text { controle caseiro } \\
\text { com aplicação de } \\
\text { sumo de fumo. }\end{array}$ & $\begin{array}{l}\text { Rotação de culturas e } \\
\text { plantio direto. }\end{array}$ \\
\hline $\mathrm{HC}$ & $\begin{array}{l}\text { Coentro, cebolinha, } \\
\text { alface, rúcula, couve, } \\
\text { tomate, pimentão, salsa, } \\
\text { cenoura, beterraba, } \\
\text { rabanete, mamão, } \\
\text { maracujá, feijão, milho } \\
\text { etc. }\end{array}$ & $\begin{array}{l}\text { Realizado por } \\
\text { enxada manual, na } \\
\text { qual se mede a área } \\
\text { em que se puxa a } \\
\text { linha de plantio, } \\
\text { abre-se a cava e } \\
\text { semeia. }\end{array}$ & $\begin{array}{l}\text { Uso de adubo } \\
\text { orgânico: esterco } \\
\text { bovino. }\end{array}$ & Retirada manual. & $\begin{array}{l}\text { Plantio direto, rotação de } \\
\text { cultura, cultivo em faixa e } \\
\text { adubação verde. }\end{array}$ \\
\hline
\end{tabular}

*A1C= Área 1 Calumbi; A2C= Área 2 Calumbi; A3C= Área 3 Calumbi; A1S= Área 1 Simplício; A2S= Área 2 Simplício; A3S= Área 3 Simplício; HC= Horta Comunitária; TAM= Técnicas agroecológicas de manejo.

Observou-se que as práticas de uso do solo são realizadas com baixos níveis tecnológicos, conforme verificado na etapa do preparo do solo, na qual é efetuada através da enxada manual por meio de capina, em todas as comunidades estudadas. Essa prática é considerada uma forma de melhorar a estrutura do solo e controlar o fluxo de espécimes invasoras. Entretanto em longo prazo, este processo tende a ser o contrario, destruindo a estrutura do solo e contribuindo para o declínio da fertilidade do mesmo (Calegari e Taimo, 2007).

O processo de nutrição do solo adotado nas hortas ocorre em sua maioria, pela utilização de adubação orgânica produzida por esterco bovino e restos de culturas, técnica agroecológica bastante utilizada para melhorar a qualidade do solo. Segundo Finatto et al. (2013), com a utilização da adubação orgânica, o solo se torna mais fértil e produtivo, aumentando sua biodiversidade, e melhorando a qualidade dos alimentos gerados a partir dessa prática.

Apesar da preocupação em se utilizar práticas sustentáveis de manejo do solo, verificou-se que na horta A1C, a nutrição do solo ocorre pela utilização de técnica convencional e tradicionalista como o uso de adubação mineral (NPK). Desta maneira, uma agricultura tipicamente sustentável, necessita-se de uma maior eficiência quanto à restrição de técnicas convencionais, que promovem uma melhoria quanto a reciclagem dos nutrientes e à produção de húmus (Aquino, 2005).

Ao longo do desenvolvimento das hortícolas é realizada a limpeza de espécimes invasora através de retirada manual na maioria das hortas e controle caseiro pela aplicação de sumo de fumo e defensivos agrícolas em alguns casos, além disso, também é realizado o controle de irrigação e eliminação de culturas que podem estar contaminadas. Segundo Amaro et al. (2007), o controle das doenças é feito por meio de um manejo adequado como equilíbrio de adubações, eliminação de restos de culturas contaminados, controle de irrigações, uso de cultivares resistentes, sementes certificadas, rotação de culturas etc.

Em relação aos atributos do solo o estudo verificou que as principais técnicas de manejo adotadas promoveram variações significativas sobre os atributos físicos do solo das hortas estudadas. Na horta HC ocorreram os maiores percentuais de umidade (16\%) em relação às demais 
hortas, denotando uma maior retenção de água no solo. Isto pode estar relacionado com a prática de adubação verde utilizada na horta, promovendo um maior incremento de umidade do solo. Segundo Von Osterroht (2002), esta prática agrícola melhora as propriedades físicas do solo devido à elevação dos teores de matéria orgânica do solo, destacando estabilidade de agregados, densidade global, porosidade, taxa de infiltração e retenção de umidade do solo.

Quando comparado com a mata nativa do cerrado observou-se que a mesma apresentou-se com os maiores percentuais de umidade do solo em relação às áreas agrícolas estudadas. Esse resultado pode ser explicado devido à mata nativa apresentar maior cobertura do solo e provavelmente, maior concentração dos níveis de matéria orgânica na superfície do solo nas áreas com maiores índices de cobertura, contribuindo para a maior retenção de água ao longo do perfil do solo e equilibrando ainda mais a concentração de matéria orgânica em relação às perdas (output).

Em relação à densidade do solo, o estudo verificou que nas hortas A2C, A3C, A1S e A2S apresentaram os maiores valores de densidade do solo em relação às demais áreas, não diferindo estatisticamente entre si (Tabela 2). O adensamento do solo pode estar relacionado principalmente pelo pisoteio no local para controle de espécies invasoras e a intensa utilização de diversas culturas nas áreas agrícolas (Costa et al., 2014).

Tabela 2. Umidade e densidade do solo das comunidades rurais do Município de Corrente, Piauí.

\begin{tabular}{|c|c|c|c|c|}
\hline Área & $\begin{array}{c}\text { Umidade do Solo. } \\
\text { P.S* } \\
\text { (\%) }\end{array}$ & $\begin{array}{c}\text { Umidade do Solo. } \\
\text { P.C* } \\
\text { (\%) }\end{array}$ & $\begin{array}{c}\text { Densidade do } \\
\text { Solo. P.S* } \\
\text { (Kg.dm }\end{array}$ & $\begin{array}{c}\text { Densidade do } \\
\text { Solo P.C* } \\
\left.\text { (Kg.dm }{ }^{-3}\right)\end{array}$ \\
\hline A1C & $9,1 \mathrm{~dB}$ & 13,8efA & $0,96 \mathrm{cB}$ & $1,4 \mathrm{bAB}$ \\
\hline A2C & $10,5 \mathrm{cdB}$ & $11,3 \mathrm{fAB}$ & $1,1 \mathrm{aA}$ & $1,6 \mathrm{abA}$ \\
\hline A3C & $14,4 \mathrm{bB}$ & $15,7 \mathrm{de} A \mathrm{~B}$ & $1,0 \mathrm{aB}$ & $1,2 \mathrm{cA}$ \\
\hline A1S & $8,7 \mathrm{eB}$ & $13,6 \mathrm{eA}$ & $1,01 \mathrm{aB}$ & $1,4 \mathrm{bA}$ \\
\hline A2S & $7,9 \mathrm{eB}$ & $15,0 \mathrm{dA}$ & 1,0abB & $1,6 \mathrm{aA}$ \\
\hline A3S & $9,2 \mathrm{~dB}$ & $18,0 \mathrm{cdA}$ & 0,99abB & $1,8 \mathrm{aA}$ \\
\hline $\mathrm{HC}$ & $16,7 \mathrm{bB}$ & $22,2 \mathrm{bcA}$ & $0,98 \mathrm{bcB}$ & $1,4 \mathrm{bA}$ \\
\hline MNC & $18,1 \mathrm{aB}$ & $39,2 \mathrm{aA}$ & $0,96 \mathrm{cA}$ & $0,99 \mathrm{dA}$ \\
\hline $\mathrm{CV}$ & $11,25 \%$ & $10,22 \%$ & $7,85 \%$ & $7,11 \%$ \\
\hline
\end{tabular}

*MNC: Mata nativa do Cerrado; A1C: Área 1 Calumbi; A2C: Área 2 Calumbi; A3C: Área 3 Calumbi; A1S: Área 1 Simplício; A2S: Área 2 Simplício; A3S: Área 3 Simplício e HC: Horta Comunitária. P.S: Período Seco; P.C: Período Chuvoso; Letras minúsculas comparam as médias entre as áreas dentro de cada período. Letras maiúsculas comparam as médias entre os diferentes períodos dentro de cada área.

Quanto à sazonalidade climática o estudo observou que tanto em relação à umidade do solo quanto à densidade os valores aumentaram significativamente no período chuvoso (Tabela 2). O aumento dos valores de umidade do solo no período chuvoso pode estar relacionado com a textura do solo da região, sendo caracterizado na maioria das áreas como argilosa, menor pratica de revolvimento do solo e a presença de matéria orgânica, possuindo alto potencial de conservação e retenção de água no solo. Já os valores de densidade do período chuvoso podem estar relacionados ao processo de compactação do solo através do impacto da gota da chuva considerada uma fonte natural de compactação, pois quando cai sobre o solo descoberto, poderá compactá-lo e desagregá-lo aos poucos (Richart et al., 2005).

O manejo utilizado no cultivo de hortaliças exerceu influência significativa sobre os teores de matéria orgânica do solo. 
Dessa forma verificou-se que a A2S apresentou os maiores valores de matéria orgânica do solo, demonstrando uma maior eficiência na adoção das praticas de manejo agroecológico sobre essa área (Tabela 3).

Tabela 3. Teores de matéria orgânicas nas diferentes comunidades de Corrente, Piauí.

\begin{tabular}{|c|c|c|}
\hline Área & $\begin{array}{c}\text { M.O } \\
\text { P.S* } \\
\text { (g.kg-1) }\end{array}$ & $\begin{array}{c}\text { M.O } \\
\text { P.S* } \\
\text { (g.kg-1) }\end{array}$ \\
\hline A1C & $2,4 \mathrm{cB}$ & 4,0bcA \\
\hline A2C & $3,1 \mathrm{bcA}$ & $2,4 \mathrm{~dB}$ \\
\hline A3C & $2,0 \mathrm{cdB}$ & $2,5 \mathrm{dA}$ \\
\hline A1S & 3,4bA & $3,5 \mathrm{cA}$ \\
\hline A2S & $4,5 \mathrm{aB}$ & $5,5 \mathrm{aA}$ \\
\hline A3S & $3,5 b B$ & $4,7 \mathrm{bA}$ \\
\hline $\mathrm{HC}$ & $1,3 \mathrm{~dB}$ & $2,7 \mathrm{dA}$ \\
\hline MNC & 2,9cB & 5,8aA \\
\hline $\mathrm{CV}$ & $10,5 \%$ & 8,95\% \\
\hline
\end{tabular}

*MNC: Mata nativa do Cerrado; A1C: Área 1 Calumbi; A2C: Área 2 Calumbi; A3C: Área 3 Calumbi; A1S: Área 1 Simplício; A2S: Área 2 Simplício; A3S: Área 3 Simplício e HC: Horta Comunitária. P.S: Período Seco; P.C: Período Chuvoso; Letras minúsculas comparam as médias entre as áreas dentro de cada período. Letras maiúsculas comparam as médias entre os diferentes períodos dentro de cada área.

O uso do manejo adequado, a manutenção da agregação do solo e as alterações no microclima em solos sob adoção de práticas agroecológicas contribuem para o acúmulo de matéria orgânica em solos não muito revolvidos, como tem sido verificado nas áreas de estudo. Desta maneira, estudos sobre o efeito de sistemas de manejo, têm demonstrado que as alterações no conteúdo de matéria orgânica do solo, são lentas, necessitando de um período de tempo relativamente longo para serem detectadas (Bayer e Bertol, 1999).

De acordo com a variação sazonal observou-se um aumento significativo em todas as áreas estudadas quanto aos teores de matéria orgânica do solo. Esse aumento pode ser explicado pelo processo de acumulação e decomposição de material orgânico nas áreas hortícolas no período de estiagem. Assim a ciclagem da matéria orgânica do solo é controlada por taxas de deposição, decomposição e renovação dos resíduos que ocorrem de forma dinâmica (Costa et al., 2013), principalmente considerando a dinâmica sazonal da região.

\section{Conclusões}

As áreas sob manejo agroecológico apresentaram variações pouco significativa quanto à utilização de técnicas sustentável de manejo do solo, na qual observa-se que nestas áreas ainda há necessidade de uma maior eficiência quanto à redução de práticas convencionais de manejo do solo.

O cultivo de hortaliças sob o uso conservacionista do solo tem promovido um incremento significativo na qualidade nos atributos físicos do solo, melhorando a estrutura e retenção de água no solo.

As estratégias de manejo agroecológico do solo têm sido eficientes no processo de incremento e conservação dos teores de matéria orgânica do solo nas horticulturas do cerrado piauiense.

\section{Declaração de conflito de interesses}

Os autores declaram não haver conflitos de interesses. 


\section{Referências}

Aquino, M. A.; Assis, R. L. Agoecologia: princípios e técnicas para uma agricultura orgânica sustentável. Brasília: Ed. Embrapa Informação Tecnológica, 2005.

Amaro, G. B.; Silva, D. M.; Marinho, A. G.; Nascimento, W. M. Recomendações técnicas para o cultivo de hortaliças em agricultura familiar. Brasília: 1. ed. Embrapa, 2007. (Circular Técnica, 47).

Bayer, C.; Bertol, I. Características químicas de um cambissolo húmico afetadas por sistemas de preparo, com ênfase à matéria orgânica. Revista Brasileira de Ciência do Solo, v. 23, p. 687694, 1999.

Calegari, A.; Taimo, J. P. C. Manual de agricultura de conservação para técnicos e agricultores. Viena: Ed. H3000 Development Consult, 2007.

Carvalho, A. J. A.; Souza, E. H.; Marques, C. T. S.; Gama, E. V. S.; Nacif, P. G. S. Caracterização física dos solos dos quintais agroflorestais e cultivos monotípicos na Região de Amargosa, Bahia. Rev. Bras. de Agroecologia, v. 2, p. 941-944, 2007.

Costa, T. G. A.; Coelho, J. V.; Iwata, B. F. Uso sustentável de áreas agrícolas no Município de Corrente, Piauí. Anais do VI Encontro de Iniciação Científica. Teresina: Instituto Federal de Educação, Ciência e Tecnologia do Piauí, Teresina, 2014.

Costa, E. M.; Silva, H. F.; Ribeiro, P. R. A. Matéria orgânica do solo e o seu papel na manutenção e produtividade dos sistemas agrícolas. Enciclopédia Biosfera, v. 9, n. 17, p. 1842-1860, 2013. Disponível em: <http://www.conhecer.org.br/enciclop/2013b/ CIENCIAS AGRARIAS/materia organica.pdf $>$. Acesso em: 10 set. 2015.
Finatto, J.; Altmayer, T.; Martini, M. C.; Mariano R. M.; Basso, V.; Hoehne, L. A importância da utilização da adubação orgânica na agricultura. Revista Destaques Acadêmicos, v. 5, n. 4, p. 85-93, 2013. Disponível em: <http://www.univates.br/revistas/index.php/ destaques/article/viewFile/818/525>. Acesso em: 10 set. 2015 .

Gliessman, S. R. Agroecologia: processos ecológicos em agricultura sustentável. Porto Alegre: Ed. UFRGS, 2000.

IBGE - Instituto Brasileiro de Geografia e Estatística. IBGE Cidades. Disponível em: $<$ http://cidades.ibge.gov.br/xtras/uf.php?coduf= 22>. Acesso em: 10 set. 2015.

Richart, A.; Tavares Filho, J.; Brito, O. R.; Llanillo, R. F.; Ferreira, R. Compactação do solo: causas e efeitos. Semina: Ciências Agrárias, v. 26, n. 3, p. 321-344, 2005. Disponível em: <http://www.uel.br/revistas/ uel/index.php/semagrarias/article/view/2319/19 97>. Acesso em: 10 set. 2015.

Stefanoski, D. C.; Santos, G. G.; Marchão, R. L.; Petter, F. A.; Pacheco, L. P. Uso e manejo do solo e seus impactos sobre a qualidade física. Revista Brasileira de Engenharia Agrícola e Ambiental, v. 17, n. 12, p. 1301-1309, 2013. Disponível em: <http://www.scielo.br/pdf/ rbeaa/v17n12/v17n12a08.pdf $>$. Acesso em: 10 set. 2015.

Von Osterroht, M. O que é uma adubação verde: princípios e ações. Agroecologia Hoje, n. 14, p. 9-11, 2002.

Yeomans, J. C.; Bremner, J. M. A rapid and precise method for routine determimation of organic carbon in soil. Communications Soil Science and Plant Analysis, v. 19, p. 14671476, 1988. 